\title{
خصائص العربية و أسرارها
}

Oleh: Yelfi Dewi*

\section{Abstract}

As a part of the language of Samiyah, Arabic has its characteristics that makes it different from other language. Among its Specific features (characteristics), Arabic bas phoneme (ashwat), vocabulary (mufradad), syntax (nabwu) and morphology (sharf). In some Arabic words, there are some specialties compared to those of other language that remains the great secret of the Arabic itself

Kata Kunci: خصائص، أسرار، العربية

وكانت سائدة في جنوب الجزيرة العربية

حتى أوائل القرن السادس للميلاد كما كانت للغة العربية إحدى اللغات السامية، وهى لغة سائدة قبل ذلك في شمالها. اللغة العربية هى اللغة

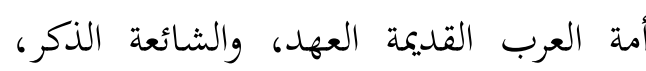
الأمة التى كانت تسكن جزيرة العرب و أخما في والتى كانت تسكن الجزيرة المنسوبة إليها فن الحقيقة ليست بجزيرة غلب عليها اسم الجزيرة، الطرف الغربي من آسيا. وهذه الأمة منها لأن كل ناحية منها محيطة بالبحار والأخمار. فقى لهري القدماء. وهم الذين يسكنون تلك الجزيرة الشرق الخليج الفارس، وفى جهة الشمال صحراء وينطقون باللغة العربية سليقة و طبعا( أحمد بلاد الشام. الهاشمى، د. ت.: 328-329). إن اللغة إن اللغة العربية لغة من اللغات الإنسانية، العربية باعتبارها إحدى اللغات السامية، تؤلف ولا شك أن لكل لغة من اللغات الإنسانية طابعا مع اللغات اليمنية القديمة و اللغات الحبشية خاصا وصفات تتصف بما سواء أكانت هذه السامية شبعة لغوية واحدة يطلق عليها اسم الصفات صالحة تعين اللغة على بلوغ أغراض الشبعة السامية الجنوبية وانتشرت في بعض أنحاء الحياة باستمرار أم كانت غير ذلك. وكذلك للغة العالم انتشارا عظيما بفضل الدين الإسلامى وما العربية خاصة و عامة تمتاز بها عن غيرها. ومن تبعه من الحضارة، ويبدو ذلك في سرعة انتشارها أهم ماتمتاز به اللغة العربية أكلا أوسع اللغات في البلدان الإسلامية. السامية تأثيرا في أصول الكلمات و المفردات، 
خختلف عناصرها عن أخواتما السامية. و أخيرا بحث عن أسرار العربية.

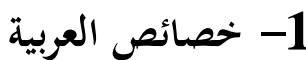

\section{أ. أصوات اللغة العربية}

تمتاز اللغة العربية عن أخواتما السامية فن أصواتها، وذلك أنه اللغة العربية أكثر أخواتما احتفاظا بالأصوات السامية، فقد اشتملت على الثلى جميع الأصوات التى اشتملت عليها أخوائما،

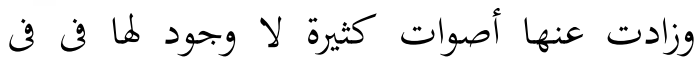
واحدة من أخواتما (على عبد الواحد وافن، د. ت: 164-165). وأنه كانت اللغة العربية

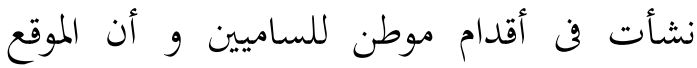
الجغرافي لهذا الموطن قد ساعد على بقائها حينا

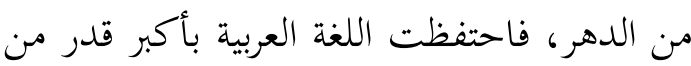
مقومات اللسان السامي الأول، فللأصوات العربية نخو خمسة عشر مخرجا( على عبد الواحد وافن، د. ت: 165-168). وقد ذكر فيها أن أن هناك أصوات اللغة العربية تخلو منها بقية اللغات

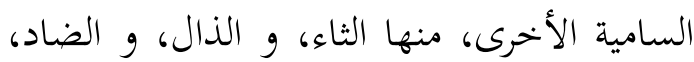
و الظاء، و الغين. وما يذكر عن الصوتين العبريين

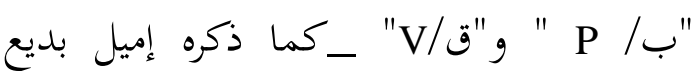
يعقوب فن كتابه_ل لا وجود لهما في اللغة العربية (إميل بديع يعقوب، د. ت. : 113)، ولعللهما غير ساميين نظرا إلى إحدى خصائص اللغات السامية التى تختص بكروف الحلق والإطباق

$$
\text { لاحروف الإذلاق. }
$$

فهى تشتمل على جميع الأصول التى تشتمل عليها أخواثما السامية أو على معظمها، هذه إلى الى

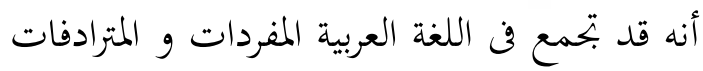

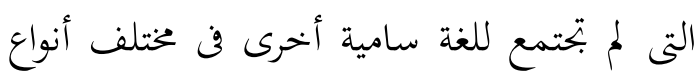
الكلمات، اسمها و فعلها و حرفها. قال ابن فارس في كتاب فقه اللغة "لغة

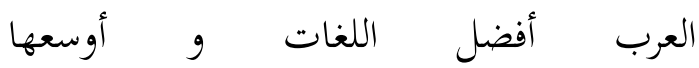
(السيوطى،1978م:321). و اللغة العربية أقدم اللغات التى ما زالت تتمتع بخصائصها من ألفاظ

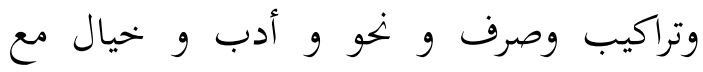
الاستطاعة فن التعبير عن مدارك العلوم المختلفة،

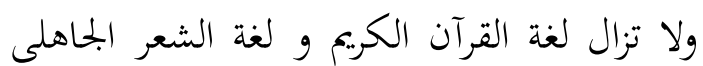

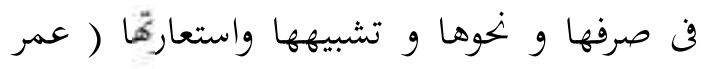
فروخ،1981م: 7-8). ولذلك سنبحث الآن خصائص العربية و أسرارها.

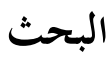

بنقسم البحث إلى قسمين يعنى

خصائص العربية و أسرارها و ترجع عناصر أية لغة إلى أمرين: الصوت و الدلالة، و تتكون الدلالة من معانى المفردات وقواعد التنظيم (النحو) و قواعد البنية (الصرف) و قواعد

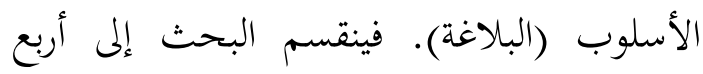

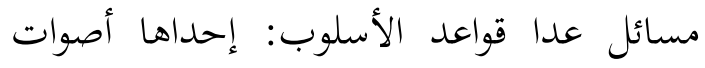

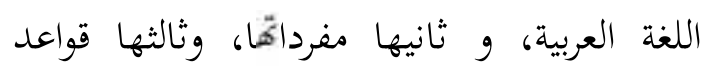

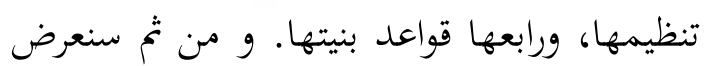

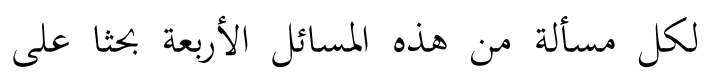

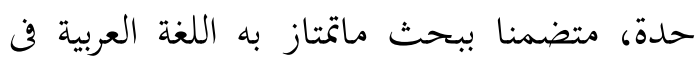


أسماء العسل جمع فيه ثمانين اسما للعسل وذكر أنه مع ذلك لم يستوعب جميع أسمائه ( عبد الحميد

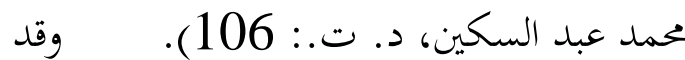
ذكر جرجى زيدان في كتابه أن السنة لها 24 اسما

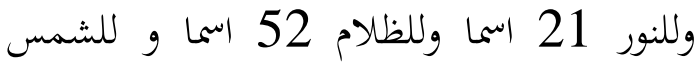
29 اسما و للسحاب 50 اسما و للمطر 84 اسما وللخمر 100 اسم (جرجى زيدان، 1988م: 33). بالإضافة إلي ذلك فإن اللغة العربية اختصت بظواهر لغوية أخرى أدت إلى كثرة مفرداتما ومعانيها، ومنها: 1- كثرة الاشتقاق، والاشتقاق في اللغة: أخذ

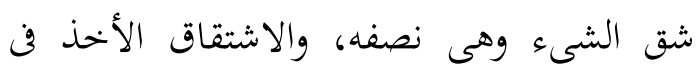

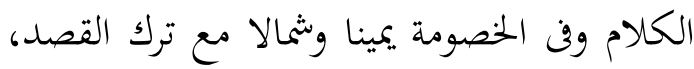

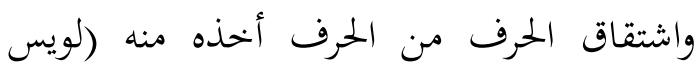
معلوف،1986م : 396 ). و فن الاصطلاح

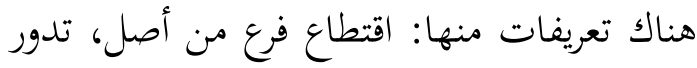
تصاريفه حول حروف ذلك الأصل وأخذ كلمة

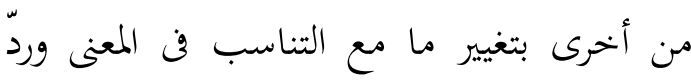

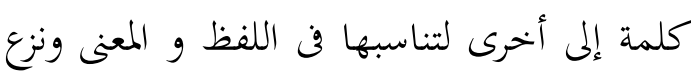

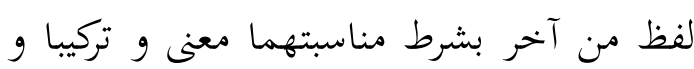

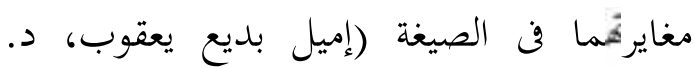
ت. :186-187). ولابد أن يكون المشتق له له أصل وأن يناسب الأصل فن الحروف والمعنى. والاشتقاق في اللغة العربية أربعة أنواع: أ) الاشتقاق الصغير أو الأصغر، وهو نزع لفظ

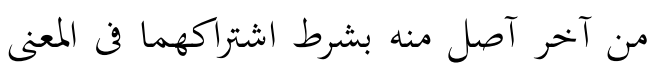

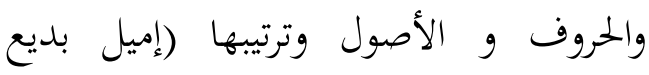
يعقوب، د. ت. :188)، كاشتقاق اسم
فعرفنا أن أصوات الحروف العربية في اللغة الفصحى و القرآن الكريم ثابتة لم تتغير ولم تتبدل منذ أربعة عشر قرنا أو أكثر. وذلك لأن قراء القرآن منذ العصر الأول قد عنوا بنطق الألفاظ وضبط الحروف من خخارجها وضبط وطريقة

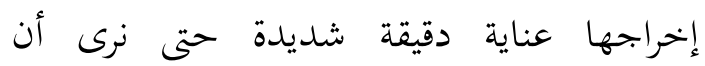

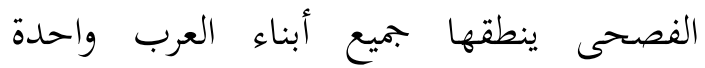
صحيحة دون تغيير ولو اختلفت لهجاتمّم السامية وكذلك يقرؤون القرآن.

\section{ب. مفردات اللغة العربية}

من أهم ما تمتاز به العربية أهما أوسع أخواتما السامية ثروة في أصول الكلمات

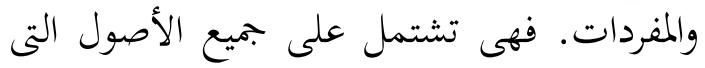
تشتمل عليها أخواتما السامية أو على معظمها،

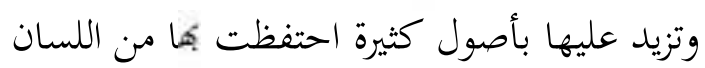

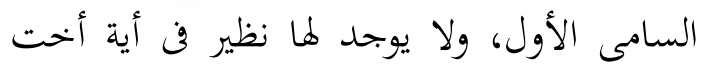

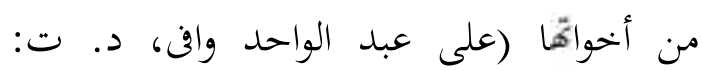
(168 وهذا إلى جانب أنه قد بتمّع لها من

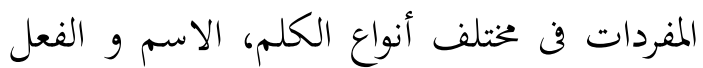
و الحرف ما لم يتجمّع مثله للغة سامية أخرى بل المبل بندر وجوده فن لغة من لغات العالم أمجع ففيها

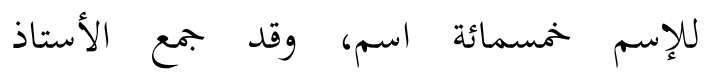
دوهامر(De Hammer) المفردات العربية المتصلة بالجمل وما يتعلق به فبلغت خمسة آلاف وستمائة وأربعة وأربعون كلمة، وهما أربعمائة اسم للداهية.

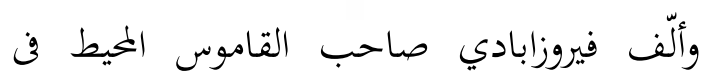


غير بحازية (على عبد الواحد وافن، د. ت:189). كلفظ " إنسان" يطلق على الواحد من بنى آدم، وعلى ناظر العين، وحد السيف، وعلى السهم، وعلى الأرض التى تزرع إلى غير ذلك.

3- التضاد، وهو أن يطلق اللفظ على المعنى وضده، كلفظ "الجون" الذى يطلق على الأبيض و الأسود (على عبد الواحد وافن، د. د.

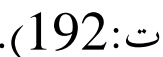

4- التعريب، إن العرب يجترئون على تغيير

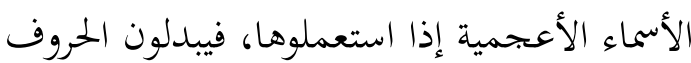
التى ليست من حروفهم إلى أقرهما مخرجا وربما أبدلوا ما بعد مخرجه أيضا، والإبدال لازم لئلا يدخلوا في كلامهم ما ليس من حروفهم. وهذا التغيير يكون بإبدال حرف بحرف أو زيادة حرف أو نقصان حرف أو إبدال حركة بحركة أو إسكان

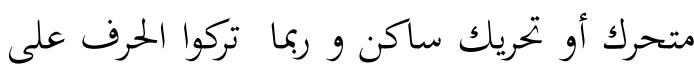
حاله لم يغيروه ( إبراهيم السامرائى، 1985م: 22- 23). والتعريب له تعريفات متعددة منها: أن تتكلم العرب بالكلمة الأعجمية على كُجها وأسلوها وأن تتكلم العرب بالكلمة الأعجمية مطلقا ونقل الكلمة من العجمية إلى العربية وأن

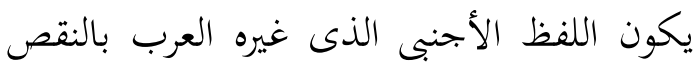
أو القلب (إميل بديع يعقوب، د. ت. :215). وذلك كلفظ "جزم" معرب من "كزم" الفارسية

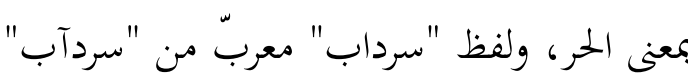
بمعنى بناء تحت الأرض، و لفظ "أرنج" معرب من "رنده" الفارسية بمعنى جلد أسود.
الفاعل "ضارب" واسم المفعول "مضروب" واسم الآلة "مضرب" وغيرها من المصدر "الضرب" عند البصريين أو من الفعل "ضرب" لريّ"

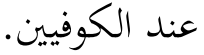
ب) الاستقاق الكبير أو القلب اللغوى، وهو أن يكون بين كلمتين تناسبا في اللفظ و المعنى دون ترتيب الحروف (إميل بديع يعقوب، د.

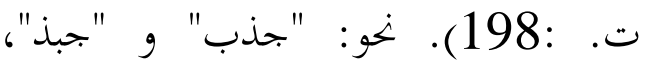
"حمد" و "مدح"، "اضمحل " و "امضحل". ج) الاشتقاق الأكبر أو الإبدال اللغوى، هو إقامة حرف مكان حرف فن موضعه (إميل بديع يعقوب، د. ت. :205)، أو اتفاق الكلمتين فن جميع الحروف عدا واحد مع تناسب المعنى بين اللفظين (على حسين

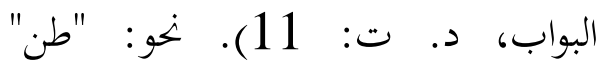
و "دن"، "نعق" و "هَق"، "السراط" و "الصراط".

د) الاشتقاق الكبار أو النحت، هو أن تنحت من كلمتين فأكثر لتدل على المعنى الذى نحت منه (توفيق محمد شاهين،1980م: 102)، أو ينتزع من الكلمتين فأكثر، كلمة جديدة تدل على معنى انتزعت منه (إميل بديع

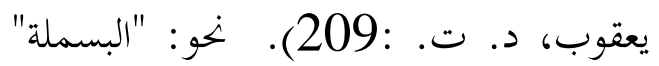

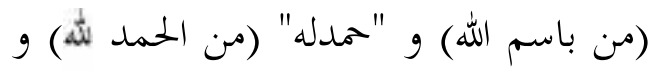
"إنما" (من إن و ما).

2- الاشتراك اللفظى، هو أن يكون للكلمة الواحدة عدة معان يطلق على كل منها على طريقة الحقيقة لا البحاز، أى لها عدة معان حقيقة 
قد احتفظت بظواهر لغوية قديمة أكثر من غيرها وظنّوا أن الإعراب من بين تلك الظواهر التى ربما تعود إلى السامية الأولى (إبرهيم أنيس، 1978:

ولما كانت اللغة العربية لغة تتوخى الإيضاح والإبانة، كان الإعراب إحدى وسائلها لتحقيق هذه الغاية، فكان إفصاحا على صلات الكلمات العربية بعضها ببعض، و عن نظم

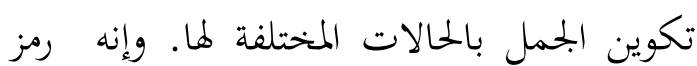
إلى معنى معين دون غيره، ولولاه لاختلطت المعانى

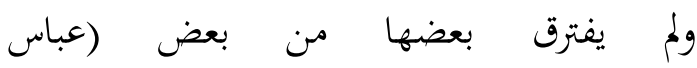
حسن، 1963 : 44 )

وفن اللغات الخالية من الإعراب يعتمد أهل اللغة على القرائن، و إلى إضافة الكلمات إلى الجملة لفهم المقصود من المعانى، ولكن الاعتماد على القوائن، و إلى إضافة لا يطرد اللبس والإمهام، فيها كما يقول اليمنى:"فأوجبت العربية التفريق بين الفاعل و المفعول، و إلا وقع اللبس و الإجمام". ويرون في الصدر "أن رجلا دخل على أمير المؤمنين على كرم الله وجهه، فقال له من غير إعراب:"قتل الناس عثمان"، فقال له

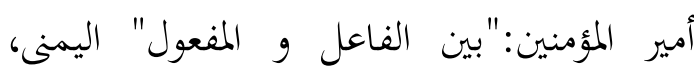
1980: 280 وبذلك لو لا الإعراب ما ميز فاعل من مفعول، ولا مضاف من منعوت، ولا تعجب من استفهام ولا صفة من مصدر، ولا نعت من تأكيد.

ويقول على عبد الواحد وافى في كتابه:"إن الإعراب أساسى من عناصر اللغة
ج. قواعد التنظيم (النحو) فى اللغة العربية تمتاز اللغة العربية في شؤون التنظيم بالقواعد الدقيقة التى اشتهرت باسم قواعد الإعراب والتى يتمثل معظمها في أصوات مد بد بـ قصيرة، تلحق أواخر الكلمات لتدل على وظيفة الكلمة في العبارة و علاقتها بما عداها من عناصر الجملة. وهذا النظام لا يوجد له نظير في أية أخت من أخواتها السامية، إلا بعض آثار ضئيلة بدائية في العبرية والآرامية والحبشية (على عبد الواحد وافن، د. ت:210).وهناك تعريفات متعددة في الاصطلاح عن الإعراب، منها "الإبانة

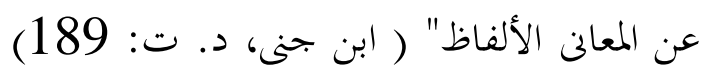
واختلاف أواخر الكلمات لاختلاف المعانى المتعاقبة عليها (محمد عبد السلام شرف شرف الدين،1984: 189) و"تغير العلامة التى في آخر اللفظ بسبب تغير العوامل الداخلة عليه وما يقتضيه كل عامل" (عباس حسن، 1963: .$(44$

والمستشرقون في بحثهم اللغات السامية و مقارنة بعضها ببعض يتخذون عادة اللغة العربية نموذجا لأقدم صورة كانت عليه شقيقائما الأخرى، وهم يفترضون أن العربية قد انعزلت فن جزيرة العرب، فاحتفظت أكثر من غيرها بظواهر سامية قديمة. أما اللغات السامية الأخرى فقد طرأ عليها من التغير والتطور ما باعد بينها وبين الأصل السامي القديم. ولعل المستشرقين حين شاهدوا الإعراب في اللغة العربية وخلق اللغات الأخرى منه قد خضعوا لمبدئهم العام من أن اللغة العربية 
أكثر من تغيرات في حركات أصواته الأصلية نفسها مع زيادة بعض أصوات عليها بدون

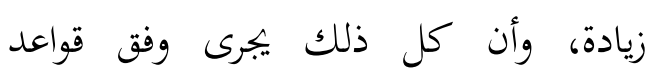

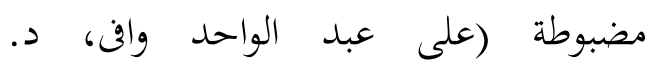
ت:216-217).

3.

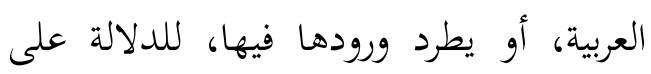

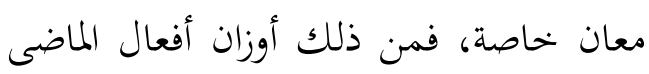

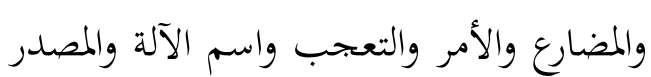
واسم الزمان والمكان وجمع التكسير.

$$
\text { 2- أسرار العربية }
$$

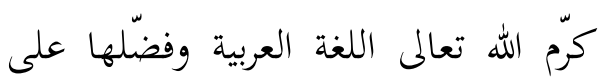
سائر لغات أهل الأرض، وهما انزل القرآن الكريم

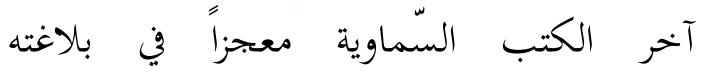
وفصاحته، بل تحدّى الإنس والحنّ على أن يأتوا

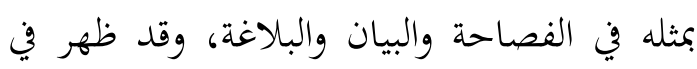
رجال العرب من اشتهر بالخطابة والبيان والإيجاز اللّغوي. ولو عدنا إلى معاجم اللّغة التّي تحوي في التيان والايحاز

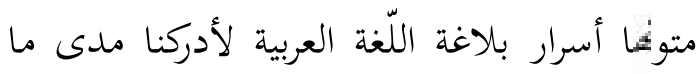

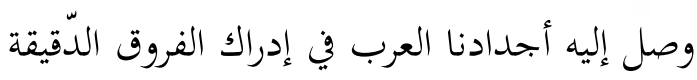
بين المعاني، والتّفريق بينها عن طريق المترادفات. فني الدّلالة على الرؤية بالعين استعملوا ألفاظاً متعدّدة قد تبدو متشابَهة في معانيها العامة إلاّ أَّهّا

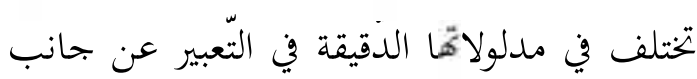
من جوانب الإبصار بالعين (عبد اللطيف
العربية، اشتملت عليه منذ أقدم عهودها. وكل ما عمله علماء القواعد هو أفم استخلصوا مناهجه

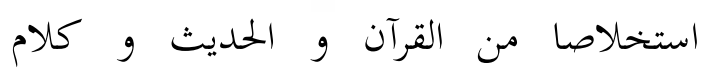
الفصحاء من العرب، ورتبوها، وصاغوها في صورة قواعد و قوانين (على عبد الواحد وافن، د. تص:215)

د. قواعد البنية (الصرف) فى اللغة العربية إن أهم ميزات اللغة العربية عن أخواتما

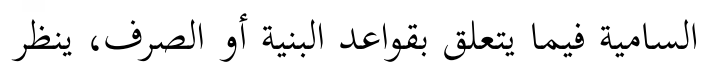
إلى ما رآه علي عبد وافي أنها ترجع إلى الأمور

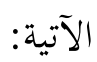

1. نظام جمع التكسير، لا يشارك اللغة

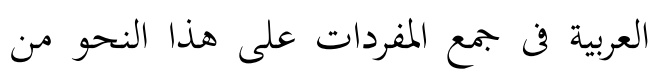

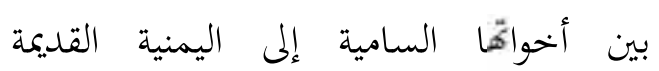

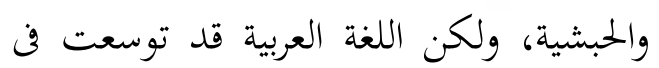

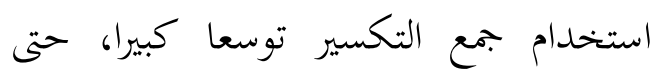

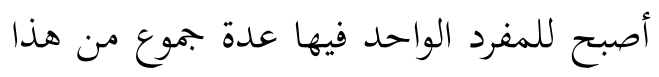
النوع. تعتبر جمع التكسير من أهم الأبواب التى تتحلى هذه الظاهرة في الكلمة العربية،

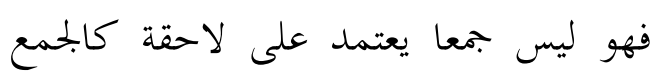

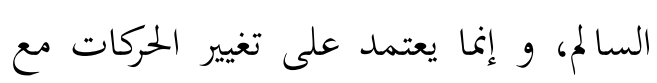
ثبات الصوامت في مواضعها، وهى بذلك يدل على مرونة اللغة العربية وخصوبتها في إنسال

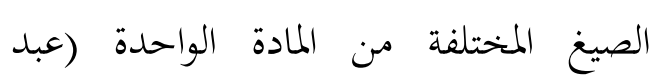
الصبور شاهين،1980: 133)

2.

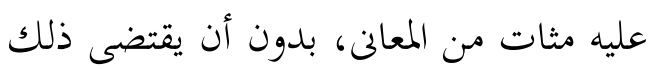


عظيماً عندما هو أيسرمنه، والعظيم قد يكون صغيراً عندما هو أعظم منه"(أبومنصورالثعالبي، وفيكا د.ت.

2- الاختصاص بعد العموم (أبومنصور الثعالبي،

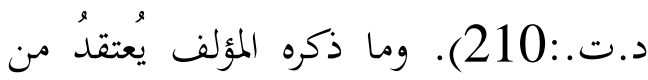
الوهلة الأولى أنه حشو في الكلام وهو أن يذكر المتكلم لفظاً عاماً، تم يأتي بلفظ خهاص اله بعلده معطوف، وهذا يسمى في البلاغة

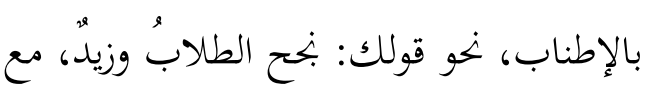
أن زيداً طالب، لكنه معطوف لغرض بلاغي، وهو التنبيه على فضل زيد على بقية الطلاب

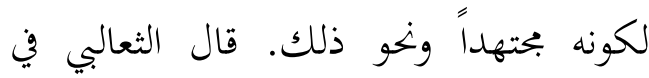
هذاالفصل ما نصه: "العرب تفعل ذلك،

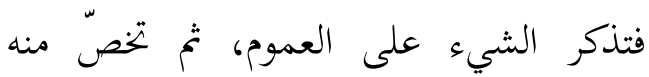
الأفضل فالأفضل، فتقول: جاء القوم والرئيس والقاضي، وفي القرآن: "حَافظوُاعَلَى الصَََّوَاتِ

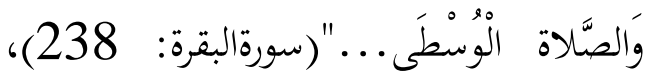

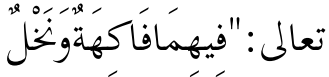
وقال

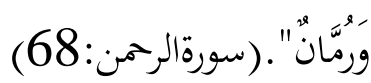
وإنما أفرد الله الصلاة الوسطى من الصلاة وهي داخلة في جملتها، وأفرد التمر والرمّان من جملة

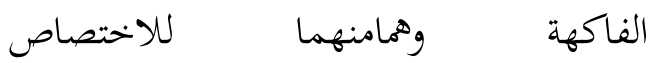

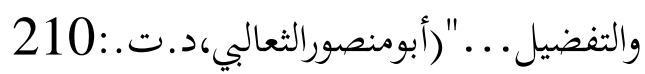

3- العموم بعد الاختصاص (أبومنصور الثعالبي،د.ت. :210). ثم قال ما نصه: "قال

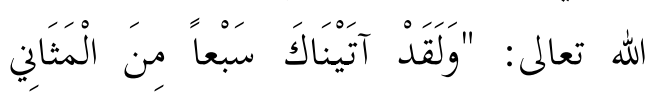

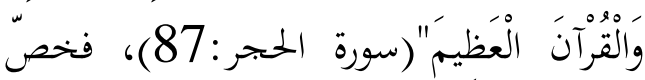

في هذا المبحث تطرق صاحب كتاب فقه اللغة وأسرار العربية أبو منصور الثعالبي إلى كثير من أسرار اللغة، وهذه الأسرار مهمة جداً لكل

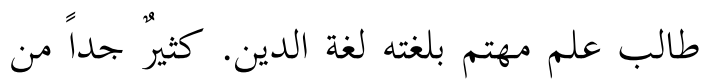
طلبة علم اللغة العربية يتعامل مع هذه الأسرار على أهما خطأ محض، والحقيقة عكس ذلك، فهي صحيحة بالدليل والبرهان كما بينه المؤلف في كتابه (فقه اللغة وأسرار العربية). أرجو أن يكون لهن في هذا البحث فائدة علمية لكل مهتم ومتتبع لأسرار اللغة، وإليك أيها القارئ الكريم هذه الأسرار : - أل

1 استقصاء ( أبو منصور الثعابي، د. ت.204)، فقد ذكر الثعالبي من المواد

اللغوية التي تستعمل في المعنى وضده في آن واحد، فكان مما جاء فيه قوله: "الغيم، المولى،

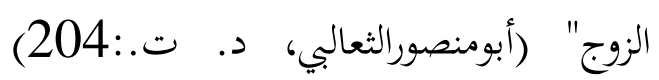

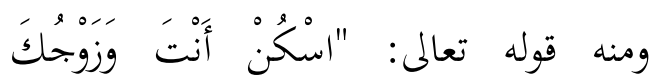
الجُنَّة...."سورة البقرة :35) فالمقصود حواء -عليها السلام- ثم ذكر - -أيضاً- أمثلة أخرى، فقال: "البيع، الوراء يكون خلف

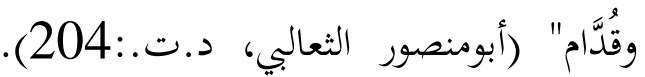

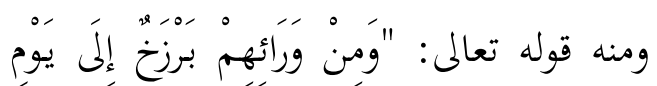

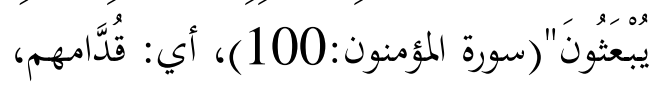
تمح ذكر الثعالبي - أيضاً- من هذه الكلمات ما نصه:"الصَّريم الليل وهو - أيضاً- الصبح لأن كلامنهما منصرم عن صاحبه، الجحلَ لَّل اليسير والجَلَّل العظيم، لأن اليسير قد يكون 
(أبومنصورالثعالبي،د.ت. :213). والعجيب أنه مع كل هذه الشواهد العربية الصحيحة

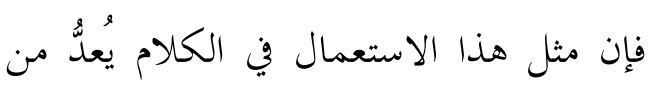
اللحن في مناهجنا فيجعلون قولك : (نصروني

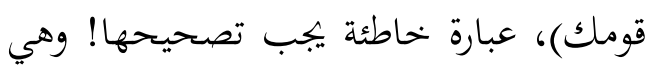
لغة من لغات العرب، وقد أوجد النحاة لها

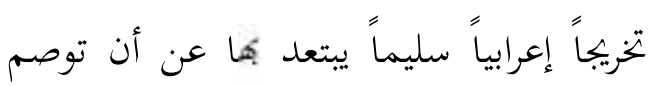

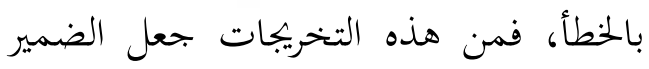

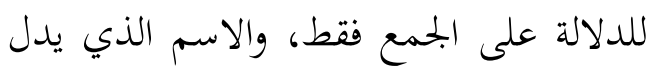
على الجمع يكون هو فاعل الفعل.

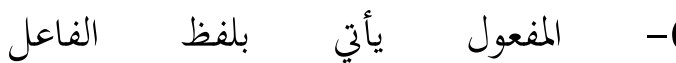
(أبومنصورالثعالبي،د.ت. :215). فني هذا

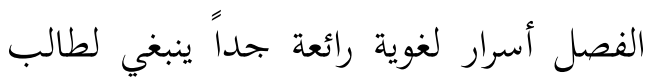

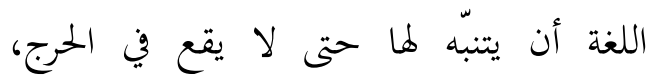
خصوصاً إذا كان متخصصاً بعلوم اللسان،

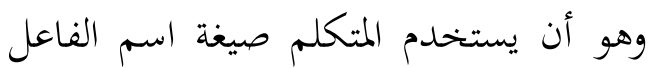
وهو يقصد اسم المفعول، وهذا مستخدم في لغة العرب، بل موجود في كلام رب العالمين في القرآن الكريم قال المؤلف تحت هذاب لقاب

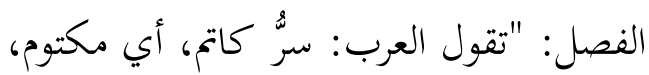

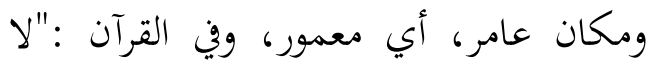

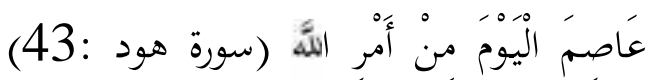

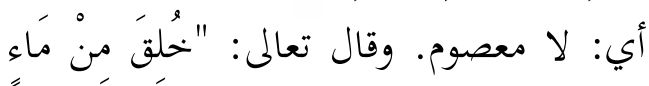

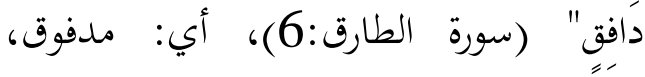

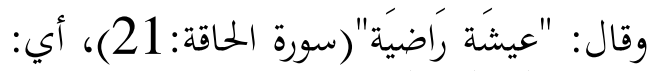

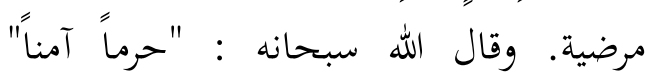
(سورةالقصص:57) أي: مأموناً. وقال جرير:
السبع، ثم أتى بالقرآن العام بعد ذكره إياها".

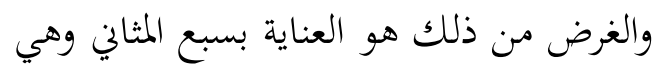
سورة الفاتحة، وهي أم الكتاب، وهي الشافية لما لها من مكانة بين سور القرآن الكريع.

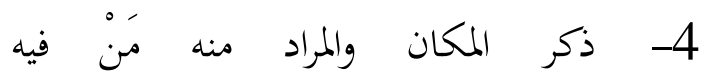

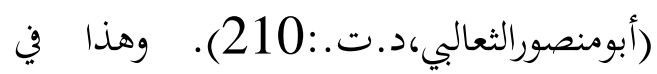
علم البيان أحد علوم البلاغة العربية ويسمى والئي

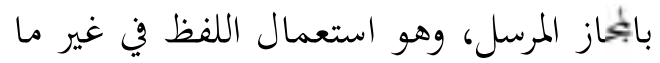
وضع له لعلاقة غير المشائمة مع وجود قرينة

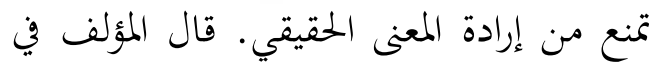
هذا الفصل ما نصه: "العرب تفعل ذلك، قال

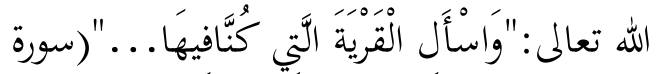

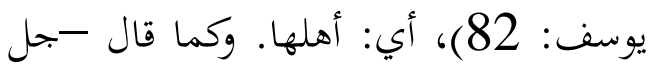

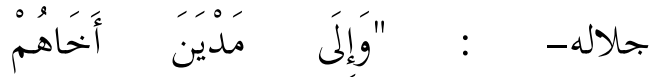

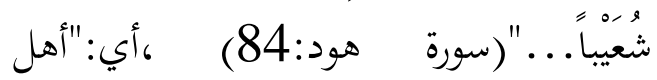
مَدْين" (أبومنصورالثعالبي،د.ت. :210). والعلاقة في الأولى مكانيّة وفي الثانيةحاليّّة.

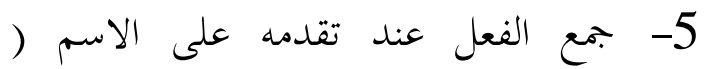

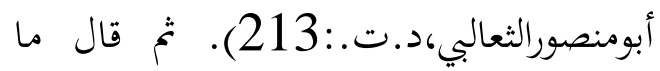
نصه: "ربما تفعل العرب ذلك، لأنه الأصل فتقول: جاؤني بنو فلان، وأكلوني البراغيث،

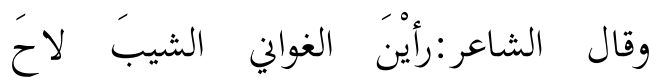
بعارضي * * * فأعرضن عني بالخدود النواضر وقال آخر :نتج الربيع محاسنا * * * ألقحنْهَا

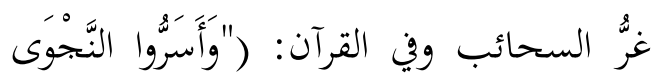

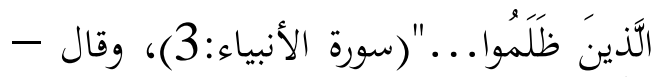

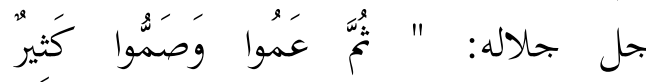
المائدة:71) (7) منُُْم..." (سورة 
إلى عشرة، نخو قوله تعالى: "سخرها عليهم

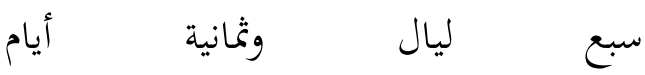
حسوماً" (أبومنصورالثعالبي،د.ت. :216). ونخو قولك: اشتريت ثلاثة أقلام وثلاث

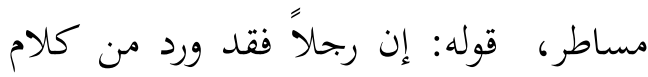

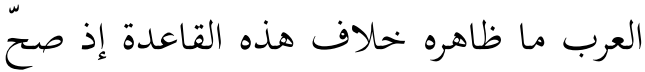
عن النبي إن رجلا قتل تسعةً وتسعين نفساً،

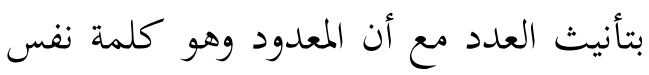

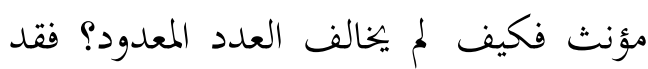
أورد لنا المؤلف السبب في ذلك في هذا الفصل، فقال ما نصه: "من سنن العرب ترك

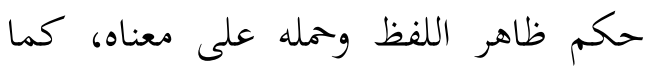
يقولون: ثلاثة أنفس، والنفس مؤنثة وإنما حملوه

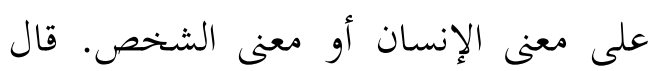

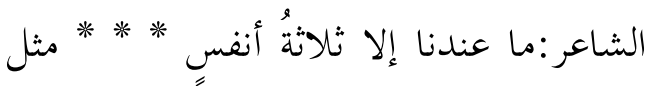

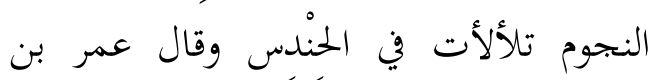

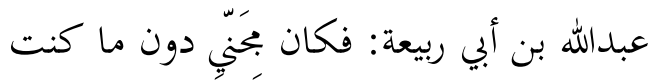
أتقي * * * *لاثُ شخوصٍ كاعبان ومعصر

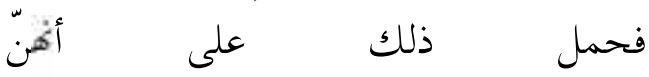

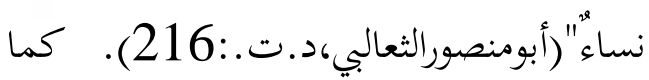
قال المؤلف بعد ذلك في الفصل نفسه بعد

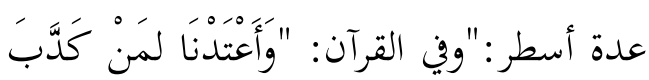

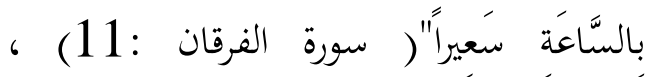

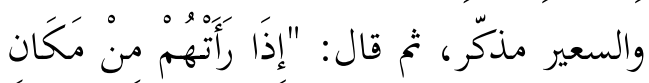

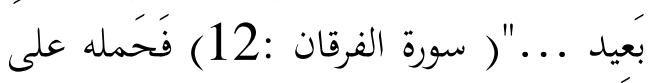

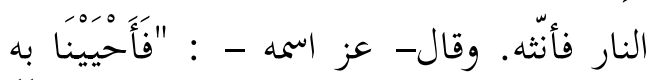

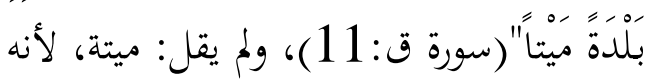
حمله على المكان، وقال- جل ثناؤه: "السماء
إن البلية من تملُّ كلامه * * * فانفع فؤادك من حديث الوامق أي : من حديث الموموق. 7- إجراء الاثنين بجرى الجمع (أبومنصورالثعالبي،

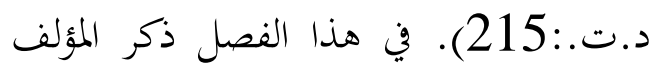
شيئاً قد يغفل عنه كثير من المختصين فضلاً على غيرهم وهو سر من أسرار هذه اللغة،

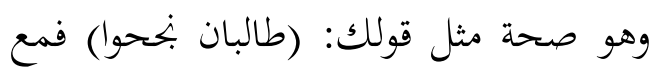
أن الاسم المتقدم على الفعل مثنى فقد لحق لحق

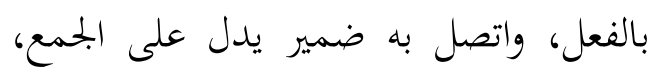
والعبارة هنا صحيحة، قال المؤلف:"قال

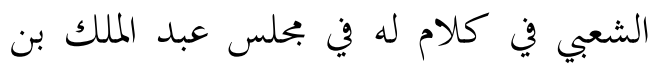
مروان: رجلان جاؤني، فقال عبد الملك:

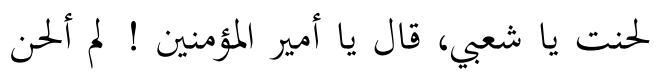
مع قول الله -عز وجل- :"هذان خصمان

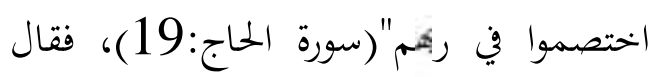

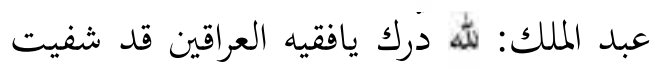
وكفيت" (أبومنصور الثعالبي،د.ت. :216). 8- ممل اللفظ على المعنى في تذكير المؤنث

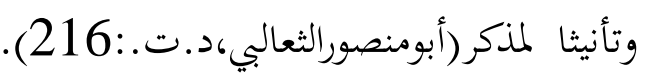
في هذا الفصل أوضح المؤلف سراً عميقاً من

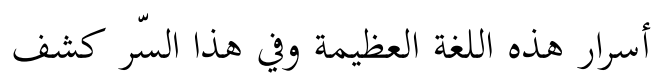
لإشكال يحدث لعامة طلبة اللغة وهو أن يُذكّر

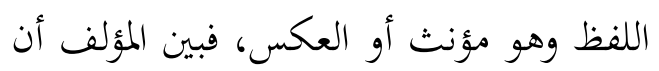

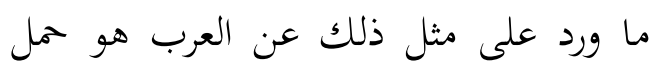

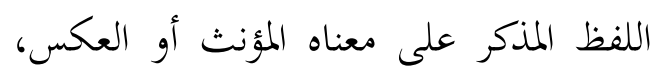
فمن هذه الإشكالات مثلاً: في القواعد المد المكاه

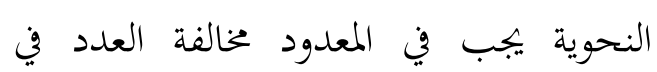
التذكير والتأنيث إذا كان العدد مفرداً من ثلاثة 
11- البحاز (أبومنصورالثعالبي،د.ت. :238).

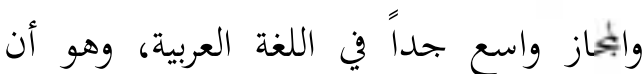

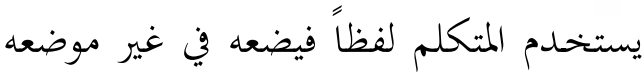
ومعناه الحقيقي في اللغة، كأن تقول:رأيت أسداً يخطب. فالأسد الحقيقي الذي لا يتكلم المعيف

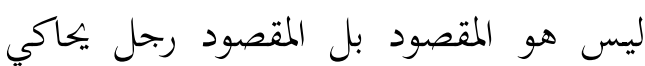

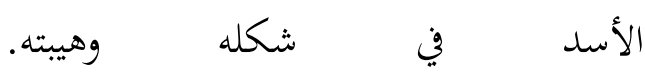
والعجيب أن ينفي بعض العلماء وجود البحاز

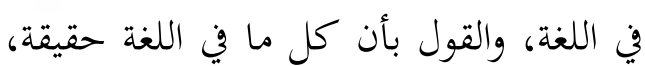

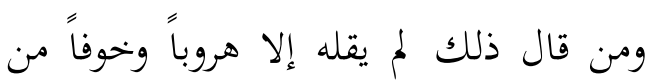

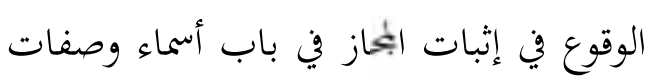

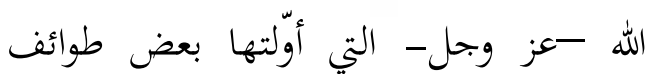

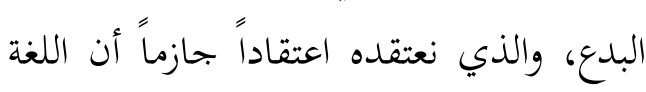
فيها بحاز والقرآن الذي نزل بهذه اللغة فيه

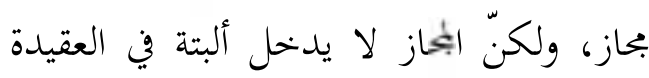
وفي باب الأسماء والصفات خحاصّة، لأن

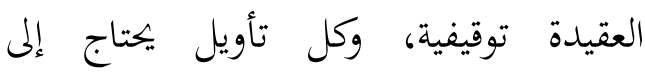
دليل.قال المؤلف في هذا الفصل ما نصه: "قال الجاحظ: للعرب إقدام على الكلام ثقة" فئ

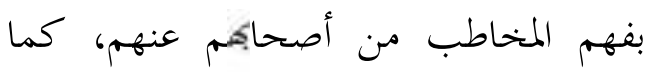

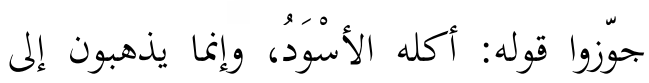
النهش واللّدغ والعض، وأُكل المالُ، و وإنما يذهبون إلى الإفناء، كما قال الله - عز واله

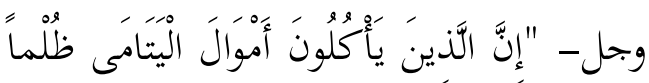

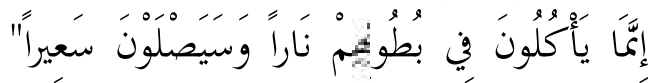
(سورة النساء :10)، ولعلهم شربوا بتلك نارك الأموال الأنبْذَة ولبسوا الحلل ...." أبومنصور

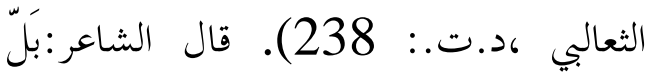

منفطر به"(سورة المزمل الآية 18).فذكّر

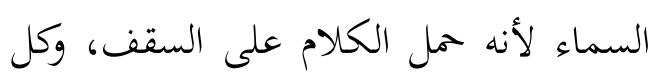
ماعلاك وأظلّك فهوسماء، و الله أعلم".

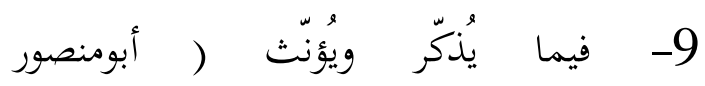
الثعالبي،د.ت.:219). ذكر المؤلف في هذا الباب ألفاظاً يجوز فيها التذكير والتأنيث، وهو دور

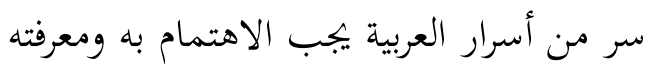

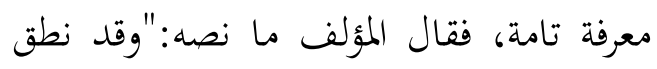

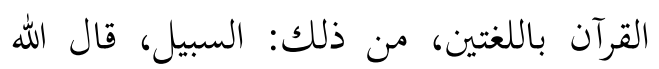

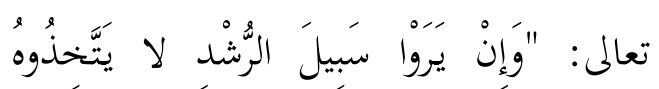

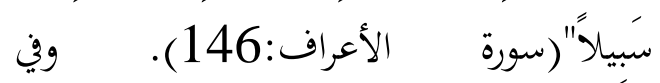

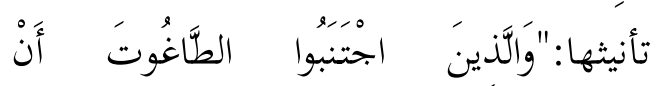

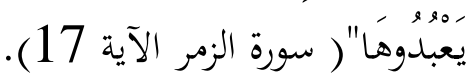

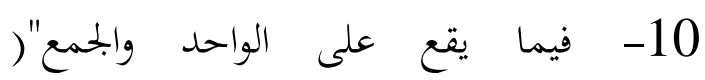
أبومنصورالثعالبي،د.ت.:219). وهذا فيعا فصل

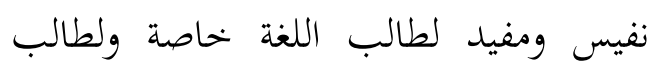
العلم عامة، ففي هذا الفصل شفاء وكفاية لمن

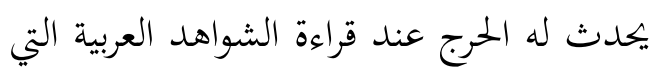
تمر عليه عند اطلاعه وقراءته، فيبحث عن الته التوجيه الصحيح لمثل هذه النصوص فقد قال

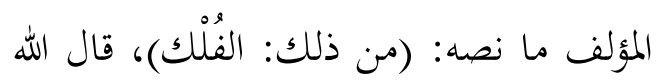

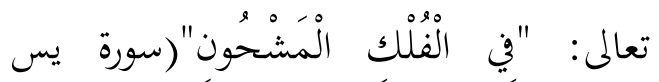

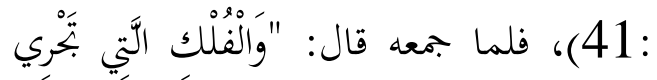

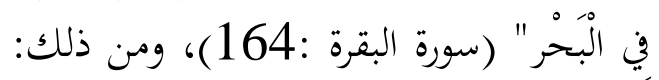

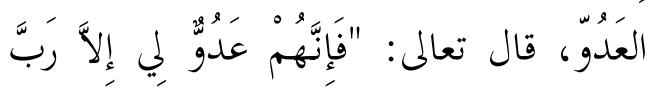

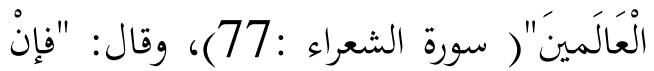

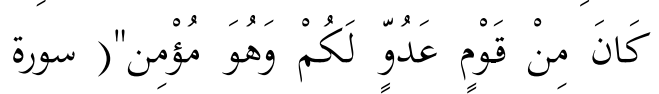
النساء :92) 
وسهل... لكي يتفاءلوا بوجودهم عندهم، وهناك بعض الأسباب التي ذكرها الثعالبي ومنها: "بعضهم إذا وُلد له ولدّ سماه بما يراه

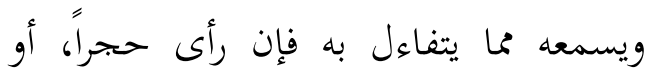
سمعه تأوّل فيه الشدة والصلابة والصبر والبقاء، فئاء وإن رأى كلباً تأوّل فيه الحراسة والألفة وبُعْدَ

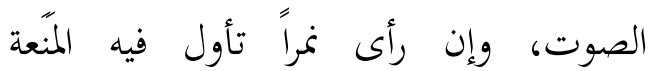

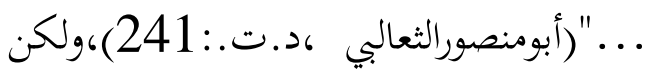
قول ابن الكلبي يكاديكون هو الأصح. 13- تسمية المتضادين باسم واحد (أبومنصور الحبح

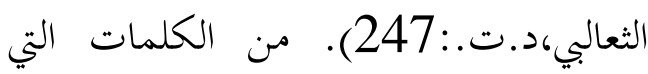
ذكرها المؤلف وهي تستخدم للمعنى ولضده

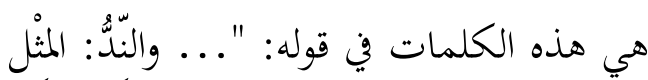

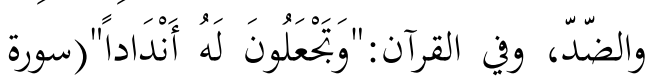
فصلت :9) على المعنيين. والزوج: الذّكر والأنثى، والقانع: السائل والذي لا يسأل، الهان.

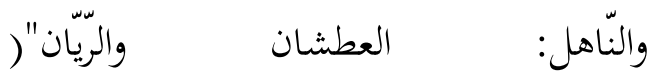
أبومنصورالثعالبي،د.ت.:247-248). وهذا وها الذي ذكره المؤلف سر من أسرار هذه اللغة.

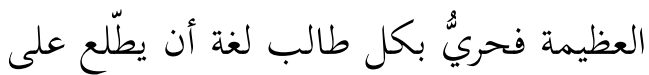

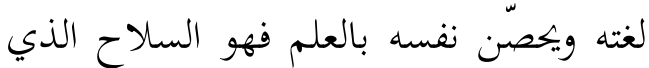

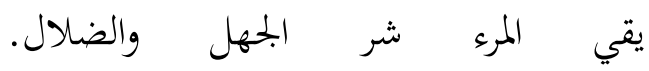
14- (الاسم يدل على الثبوت والاستمرار،

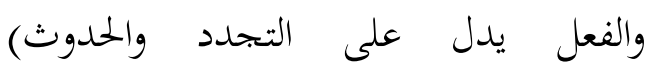
على المتكلم أن يكون بليغاً وأن يضع الكلام

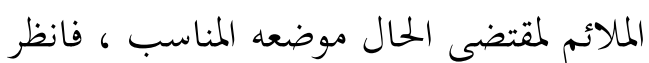

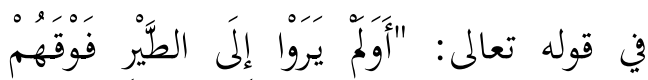

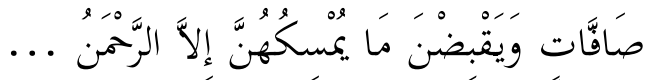

السراويل من خوف ومن دهش * * *

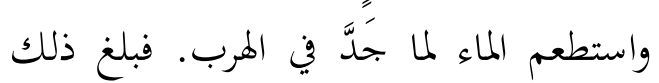

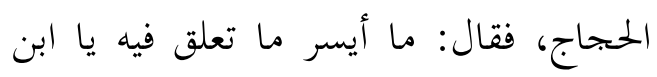

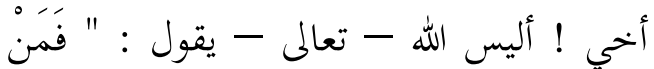

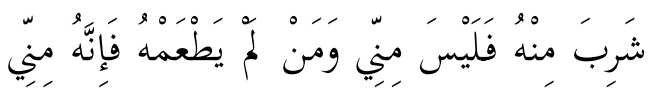

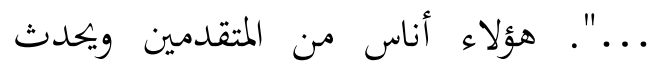
عندهم خلط! وانظر إلى البعد الزمني بينا وبينهم، فماذا عسانا أن نقول عن المتأخرين!

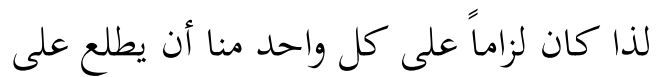
لغته وأسرارها وخفاياها وخباياها.

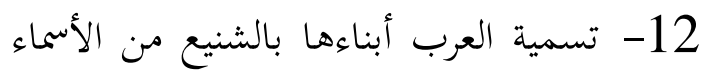

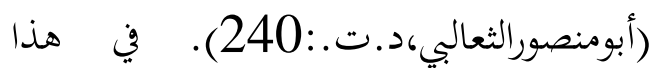
الفصل إجابة شافية وكافية من المؤلف لسؤال يجبول في خاطر الكثيرين، وهو أنه كيف يقوم

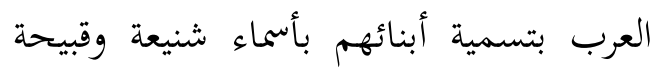

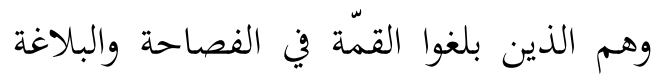

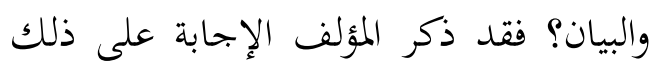

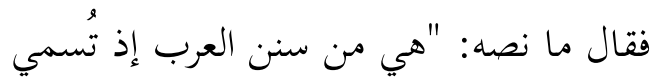

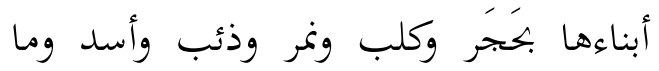
أشبهها ..." (أبومنصور الثعالبي،د.ت. :240)، بعد ذلك بعدة أسطر

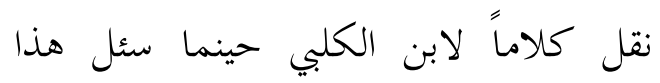
السؤال فقال:"لأفها سمّت أبناءها لأعدائها،

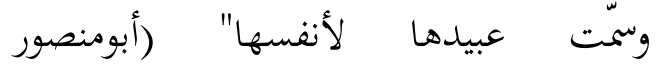
الثعالبي،د.ت.: 241).العرب معروف عنهم التشاؤم والتفاؤل فهم يسمون أنفسهم أسماء

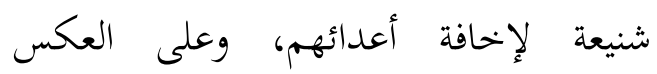

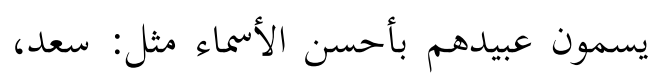


الثبوت والاستمرار، أما الفعلية فإنها تدل على التجدد والحدوث.

16-(لا يلزم في التشبيه أن يكون المشبه به

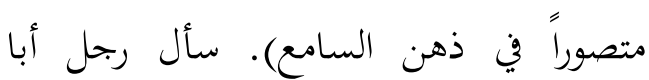

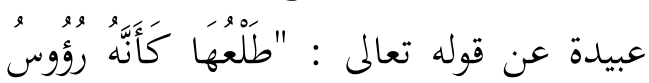

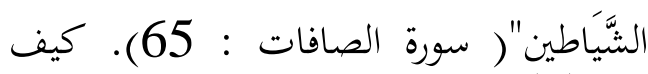

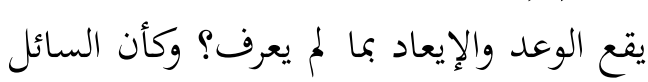
يستغرب بحيء المشبه به (رؤوسُو الشَّيَاطين)

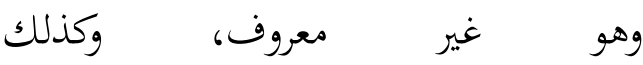

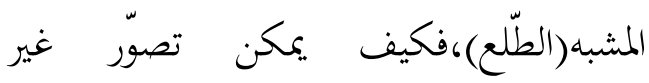
المعروف!. فأجاب أبو عبيدة: إنما كلم الله -

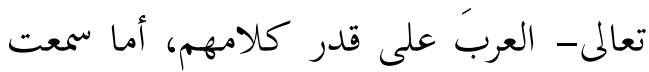
قول امرئ القيس يتّوعد رجلاً هدده بالقتل:

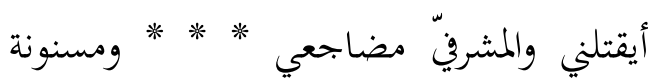
زرق كأنياب أغوال وهم لم يروا الغول قط ، إنسي

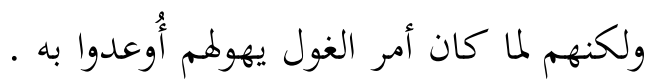
فاستحسن الجالسون ذلك ، وعزم أبو عبيدة من ذلك اليوم أن يؤلّف كتاباً في مثل هذا وعزم الئ عيداه وأشباهه، فلما رجع إلى البصرة ألّف كتابه

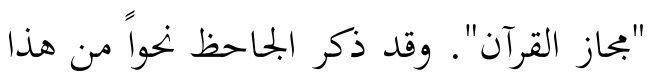
الكالام فقال(66): "فقال أهل الطعن والخلاف : كيف يجوز أن يضرب المثل بشيء

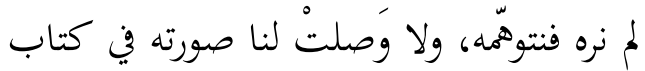
ناطق. أو خبر صادق. ومخرج الكلام يدل على التخويف بتلك الصورة، والتفريع منها. وعلى أنه لو كان شيء أبلغ في الزجر من

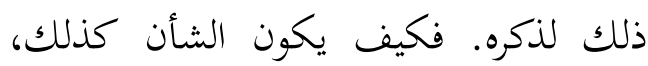
والناس لا يفزعون إلا من شيء هائل شنيع،
"( سورة الملك : 19). فقد عبّر الله - عز وجل - عن حال الطير في السماء بما يناسبه، فصفُّ الجناحين؛ لأنه الثابت والمستمر لملدة طويلة عبّر عنه باسم فقال:"صافات" فينات ، أما

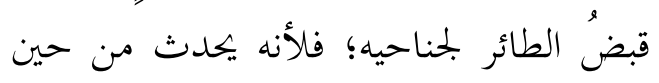

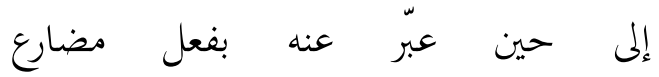
وهو "يقبضن"،فلم يقل:يقبضن صافات، بل قال: " صافاتٍ ويقبضن" . ومن أجل ذلك بيّن أهل البلاغة أنّ سلام إبراهيم - عليه السلام - أبلغ من سلام الملائكة، وذلك إنك

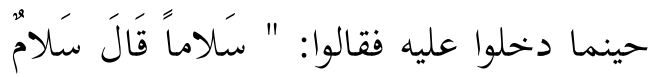
. . "( سورة الذاريات : 25) فجملة الملائكة جملة فعلية إذ التقدير : نسلم عليك

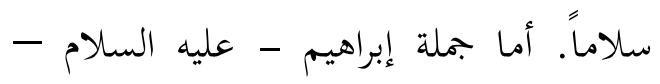
فهي اسمية إذ التقدير : سلامٌّ عليكم، فدعوا

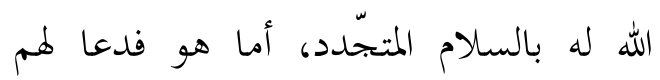
بالسلام الثابت. والفرق واضح وجليٌ. 15- (دخول "هل" الاستفهامية على الجملة الاسمية) .الأصل في "هل" الاستفهامية دخولها على الجملة الفعلية، فتقول: هل صلّيت الفجر؟. وهذا استفهام حقيقي تكون إجابته إما بنعم ، أو بلا. أما عند دخول "هل" على لى له جملة اسمية فإن دخولها يكون لغرض بلاغي.

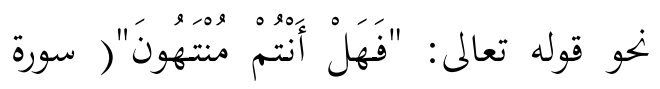
المائدة : 91) فدخلت على جملة اسمية -

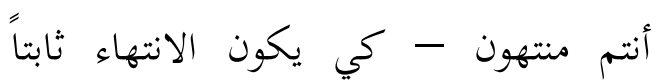
ومستمراً كما هو متقرر من فائدة الاسم ودلالته، وهي أن الجملة الاسمية تدل على 
الصعاليك، وأنت شبهته بكم فهذا انتقاص من

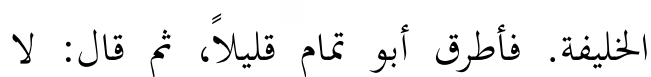
تنكروا ضربي له من دونه ** * * مثلاً شروداً والباس الندى

فالهه قد ضرب الأقل لنوره ** * مثلاً من المشكاة والنبراس فعرف الفيلسوف الكندي أن هذا الرجل داهية،فقال: إنه لن يعمر طويلاً ؛ لأن عقله يأكل من عمره. القصة وضّحت لنا أنه لا يلزم في التشبيه أن يكون المشبه به أفضل، ولكن يجب أن يكون الأشهر.

الحخلاصة والاختتام

إن فيما تقدم في هذا البحث بصدد

خواص اللغة العربية وصيانة أصواتما وغزارة مفرداتما ودفة قواعدها النحوية وخصب مناهجها الصرفية كالظواهر التى تدل بوضوح على سيادة اللغة العربية بين أخواتما السامية من ناحية عناصرها اللغوية. كذلك بأسرار العربية و التى بـن توجد فن كثير من آيات القرآن الكريم بأسلوب

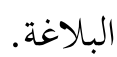

بانتهاء إعداد هذا البحث، نرجو أن ننتفع به علوما كثيرة إما معرفة أخوال اللغات السامية على وجه عام واللغة العربية على وجه خاص.

السامرائى، إبراهيم، ف التعريب و المعرب، بيروت: مؤسسة الرسالة، 1985م، ط 1
قد عاينوه، أو صوّره لهم واصف صدوق

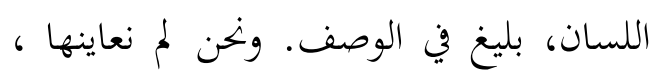

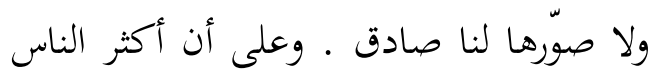
من هذه الأمم التي لم تعايش أهل الكتابين

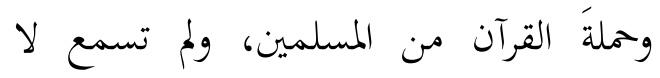
يتوهمون ذلك، ولا يقفون عليه، ولا يفزعون

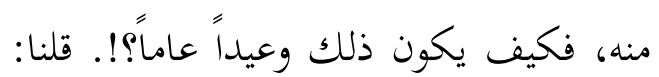

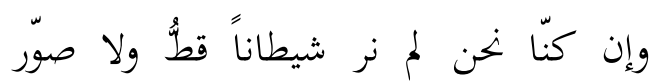
رؤسها لنا صادق بيده، ففي إجماعهم على ضرب المثل بقبح الشيطان، حتى صاروا يضعون ذلك في مكانين، أحدهما أن يقولوا: "لهو أقبح من الشيطان"، والوجه الآخر أن يسمى الجميل" شيطاناً على جهة التطيٌّ له، كما تسمّى الفرس الكريمة شوهاء، و والمرأة الجميلة صمّاء.... وأشباه ذلك على جهة التطيُّ له، ففي إجماع المسلمين والعرب وكلِّ من لقيناه على ضرب المثل بقبح الشيطان، دليل" على أنه في الحقيقة أقبح من كل قبيح".

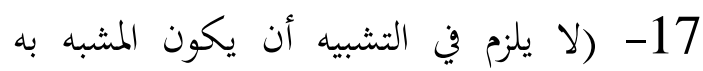
أفضل من المشبه) ألجم أبو تمام الحاضرين عند المعتصم حين مدح المعتصم بقصيدة كان منها

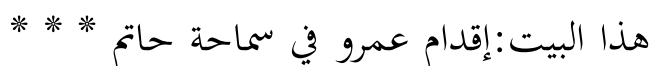

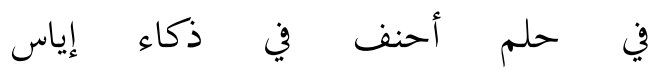
قال الحاضرون: الخليفة يفوق

أنيس، إبراهيم، من أسرار اللغة، القاهرة: مكتبة

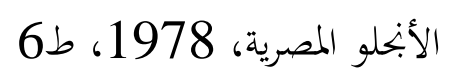


البواب، على حسين، ظاهرة الإبدال اللغوى، الرياض: دار العلوم للطباعة و الشر، د. ت

وافن، على عبد الواحد، فقه اللغة، القاهرة: دار

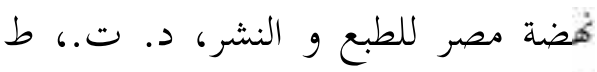

8

فروخ، عمر، عبقرية اللغة العربية، بيروت: دار

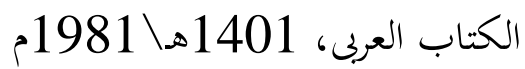

معلوف، لويس، المنجد في اللغة و الأعلام،

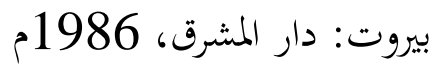

المبارك، محمد، فقه اللغة و خصائص العربية،

بيروت: دار الفكر الحديث، 1964.

الدين، محمد عبد السلام شرف، الإعراب و التركيب بين الشكل و النسبة، القاهرة:دار

المرجان للطباعة، 1984.

الجاحظ، البيان والتبيين. ج2

النادى الأدبى. 2007. من أسرار العربية وفرائدها

(Online), (http://www.adabail.com, diakses 15 september 2009)

$$
\text { عبد اللطيف السعيد. مقالات في اللغة والتربية. }
$$

(Online), (http://www.saaid.net, diakses 15 September 2009
ابن جنى، الخصائص، بيروت: دار الهدى للطباعة

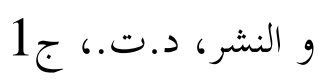

الهاشمى، أحمد، جواهر الأدب فن أدبيات و إنشاء لغة العرب، لبنان: دار الفكر، د.ت.، الفيات التهاء

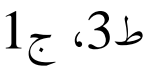
يعقوب، إميل بديع، فقه اللغة العربية و خصائصها، بيروت: دار الثقافة الثقانة الإسلامية، د.ت.

شاهين، توفيق محمد، عوامل تنمية اللغة العربية، القاهرة: مطبعة الدعوة الإسلامية، 1980م

زيدان،جرجى، اللغة العربية كائن حي، بيروت: دار الجيل، 1988م، ط2 الميل

السيوطى، جلال الدين، المزهر في علوم اللغة و

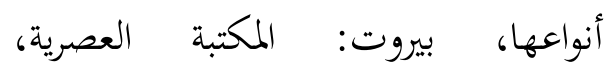

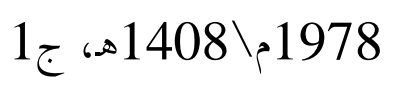

حسن، عباس، النحو الوافى، القاهرة: دار

$$
\text { المعارف، 1963، ج ج } 1
$$

السكين، عبد الحميد محمد عبد، فقة اللغة، مصر : مطبع الأمانة، د. ت. شاهين، عبد الصبو، المنهج الصوتى للبنية الغربية، بيروت: مؤسسة الرسالة، 1980 
